\title{
Exploring the dropout rates and causes of dropout in upper-secondary technical and vocational education and training (TVET) schools in China
}

\author{
Hongmei Yi ${ }^{a}$, Linxiu Zhang ${ }^{a, *}$, Yezhou Yao ${ }^{a}$, Aiqin Wang ${ }^{b}$, Yue Ma ${ }^{c}$, Yaojiang Shi ${ }^{c}$, \\ James Chu ${ }^{\mathrm{d}}$, Prashant Loyalka ${ }^{\mathrm{d}, \mathrm{e}}$, Scott Rozelle ${ }^{\mathrm{c}, \mathrm{d}}$ \\ ${ }^{a}$ Center for Chinese Agricultural Policy, Institute of Geographical Sciences and Natural Resource Research, Chinese Academy of Sciences, China \\ ${ }^{\mathrm{b}}$ Northwest Socioeconomic Development Research Center, Northwest University, Xi'an, China \\ ' Center for Experimental Economics in Education, Shaanxi Normal University, Xi'an, China \\ ${ }^{\mathrm{d}}$ Freeman Spogli Institute for International Studies, Stanford University, Stanford, United States \\ e School of Education Science, Henan University, China
}

\section{A R T I C L E I N F O}

\section{Article history:}

Received 15 May 2013

Received in revised form 13 March 2015

Accepted 27 April 2015

\section{Keywords:}

Technical and vocational education and training (TVET)

High school

Dropout

China

\begin{abstract}
A B S T R A C T
Policymakers in many developing countries regard upper-secondary technical and vocational education and training (TVET) as a key element in economic growth and poverty reduction. Unfortunately, there is evidence that upper-secondary TVET programs in developing countries experience high rates of dropout. The overall goal of this study is to examine the dropout rates and reasons for dropout among uppersecondary TVET students in China. To meet this goal, we have three specific objectives. First, we seek to produce high-quality estimates of dropout rates among students in upper-secondary TVET schools in one coastal and one inland province of China. Second, we seek to identify which students drop out from upper-secondary TVET. Third, we test whether financial constraints, math and computer achievement, and parental education and migration status correlate with TVET dropout. Drawing on data from a survey of 7414 upper-secondary TVET students in two provinces of China, we find dropout rates of $10.7 \%$ across both provinces and as high as $22 \%$ in poorer inland areas, suggesting major gaps and disparities in Chinese TVET dropout rates. Furthermore, we find that baseline academic performance and maternal education and migration status are strong correlates for student dropout.
\end{abstract}

(C) 2015 Elsevier Ltd. All rights reserved.
Policymakers in many developing countries regard uppersecondary technical and vocational education and training (TVET) as a key element in economic growth and poverty reduction. ${ }^{1}$ For example, the Brazilian government recently launched the National Program of Access to Technical Education and Employment (Pronatec), which will invest more than 600 million US dollars in upper-secondary TVET and expand enrollment by 8 million

\footnotetext{
* Corresponding author at: Room 3822, No. Jia 11, Datun Road, Chaoyang, Beijing 100101, China. Tel.: +86106488 9834; fax: +861064856533.

E-mail address: lxzhang.ccap@igsnrr.ac.cn (L. Zhang).

1 Our definition of upper secondary TVET in our paper is identical to that used by OECD countries (Kuczera and Field, 2010). Secondary education consists of lower secondary education (or junior high school) and upper-secondary education (or high school). Upper-secondary education may be further split into general programs (or academic schools) and TVET programs (or upper-secondary TVET schools).
}

students before 2014 (National Congress, 2011). The Indonesian government aims to increase the share of TVET in upper-secondary education to $70 \%$ (from 30\%) by 2015 as a means to reduce youth unemployment (Ministry of National Education, 2006). International development organizations, including the Asian Development Bank (ADB) and the United Nations Educational, Scientific and Cultural Organization (UNESCO), have advocated for uppersecondary TVET as an effective means to promote economic growth and poverty reduction in developing countries (ADB, 2008; UNESCO, 2012a).

Education officials in China, like elsewhere in the world, have made it clear that upper-secondary TVET is supposed to play an important role in the nation's education strategy. In fact, China has one of the most ambitious upper-secondary TVET programs in the world today. During the early 2000s, enrollment increased from 5 million students (in 2000) to 7.3 million students (in 2011-National Bureau of Statistics, 2001, 2012). During this time 
period, spending per student in upper-secondary TVET also increased dramatically. In 2000, government spending per upper-secondary TVET student was roughly 300 dollars (National Bureau of Statistics, 2001). In 2011, government spending per upper-secondary TVET student increased to more than 850 dollars (National Bureau of Statistics, 2012).

Despite the high profile of upper-secondary TVET in China (and elsewhere) over the past decade, policymakers and researchers have been concerned that upper-secondary TVET dropout rates remain high. In fact, similar to the situation in a number of other developing countries (e.g., Pakistan, India, Ethiopia, Kenya and Albania, see Janjua and Mohammad, 2008; ACE Europe, 2008; Jordan et al., 2009; UNESCO-UNEVOC, 2012), high dropout rates in upper-secondary TVET have begun to be reported (Wang, 2012; Gao, 2011). This is despite steady increases in financial aid and reductions in tuition rates, which reduce the cost of attending upper-secondary TVET (Fo and Xing, 2011).

Dropout is considered a serious problem for two reasons. First, dropout reduces the number of individuals who actually complete upper-secondary TVET. To the extent that the goal of economic growth and poverty reduction requires individuals to complete (and not just attend) upper-secondary TVET, dropout undermines the goals of policymakers. Indeed, retention is considered a key metric in evaluating upper-secondary TVET (UNESCO, 2012b). Second, the fact that families are withdrawing their children from upper-secondary TVET suggests deficiencies in TVET value-added. Granted, actual dropout choice behavior involves factors beyond cost-benefit calculations. However, it is likely that families enroll their children in upper-secondary TVET out of cost-benefit calculations (as the whole mission of upper-secondary TVET is to train a student for a specific skill and increase future earnings). Thus, if students and their guardians decide whether to stay in or leave upper-secondary TVET based on the costs and benefits of attending, dropout rates could reflect perceived lack of benefits from these programs. Indeed, several scholars are concerned that many of China's upper-secondary TVET schools are contributing little value-added to their students (Guo and Lamb, 2010; Kuczera and Field, 2010; Wang, 2012).

Just how high is the dropout rate? There are two studies, each with their own limitations, which have attempted to measure the dropout rate in upper-secondary TVET schools in China. First, using data reported by local county governments and schools, Wang (2012) finds that the dropout rate for the three years of uppersecondary TVET schooling in 2007 was $18.7 \%$ across the nation and $28.0 \%$ in western China. Second, based on a survey of one uppersecondary TVET school in Jiangsu province, Gao (2011) reports that the cumulative dropout rate is $15 \%$. While these findings are important, the first study is limited by the fact that data reported by local county officials and schools has been shown to lead to downwardly biased estimates of dropout (Yi et al., 2012). This is because school and local government officials may be incentivized to overstate the numbers of their enrollments and graduates. The second study is limited by its lack of generalizability (as it was focused on dropout rates only at one school). As such, to the best of our knowledge, there are no accurate estimates of dropout rates in Chinese upper-secondary TVET to date.

More importantly, beyond knowing the rate of dropout, it is also important to study the correlates of dropout. An analysis of who is dropping out of upper-secondary TVET schools is essential in identifying high-risk students. Knowing why students drop out is a first step in designing interventions to curb dropout rates. Surprisingly, to our knowledge, no study has attempted to explore the potential determinants of dropout in the Chinese context. Although a few studies (such as Gao, 2010, 2011; Ye, 2002) offer qualitative assessments on why students drop out as well as policy suggestions for preventing dropout, these case studies may lack external validity because they are based on single cases (e.g., only one or two schools). The studies also provide little guidance as to how these schools were sampled. Moreover, scholars relying on data reported by local officials and schools may be unable to perform analyses on the determinants of dropout, as they lack sufficiently detailed data on parental, student, teacher, and school background factors.

The overall goal of this study is to understand the dropout rate and reasons for dropout among upper-secondary TVET students. To meet the goal, we pursue three specific objectives. First, we seek to produce high-quality estimates of dropout rates among students in China's upper-secondary TVET schools. Second, we seek to identify which students drop out from upper-secondary TVET. Third, we explore the potential determinants of upper-secondary TVET dropout.

To achieve our objectives, we collected and analyzed panel data from a large and representative survey of upper-secondary TVET students and schools in one western and one eastern province of China. Our descriptive results indicate that dropout rates are especially high in western China compared to eastern China. Our multivariate results indicate that dropout is not primarily determined by financial constraints but is rather determined by the level of education and migration status of the parents of the students. Dropout is also shown to be negatively associated with student achievement. That is, our results indicate that students with higher achievement are less likely to drop out than students with lower achievement.

The remainder of the paper is structured as follows. Section 2 discusses our hypotheses for why students in upper-secondary TVET are dropping out. Section 3 describes our data and statistical methods. Section 4 presents our results. Section 5 concludes with discussion.

\section{Hypotheses}

Our first hypothesis is that students drop out because they are financially constrained: families are unable to shoulder the financial costs (whether direct or indirect) of sending their children to upper-secondary TVET in China. Although compulsory education (grades 1-9) in China was made free in 2008, uppersecondary education was not, and thus households are still responsible for paying all high school fees (Connelly and Zheng, 2003; Hannum, 2003; Liu et al., 2009). The cost of attending uppersecondary TVET, including tuition fees, room and board and textbooks, can reach as high as 4000 RMB per year (roughly 645 dollars-Kuczera and Field, 2010). To put this amount in context, in 2009, the rural per capita net income was 5153 RMB (roughly 831 dollars-China National Bureau of Statistics, 2010). That means, even if excluding living expenses, the cost of attending TVET is around $80 \%$ of the annual income of a student's family (Liu et al., 2009).

Although financial aid has been offered for upper-secondary TVET students in recent years (Kuczera and Field, 2010), not all students receive this support. China's TVET policies state that poor students should receive 1500 yuan (240 USD) in each of the first two years at school (Kuczera and Field, 2010). The policy also suggests that students under a poverty threshold also should receive full tuition waivers (Fo and Xing, 2011). The government

\footnotetext{
${ }^{2}$ While Yi et al. (2013) do not provide a full explanation for why targeting is so poor, one potential reason is that the system to allocate financial aid requires students to submit a substantial amount of paperwork. Like other financial aid programs, such a system sometimes misses poor students who are less knowledgeable about or have less support to fill out and submit required paperwork (Dynarski and Scott-Clayton, 2008; Li et al., 2013; Loyalka et al., 2013).
} 
pledged nearly 4.5 billion yuan (750 million dollars) to subsidize upper-secondary TVET schooling for poor students in 2010 (China State Council, 2010). However, in a recent study, Yi et al. (2013) found that more than $34 \%$ of the poorest students in TVET schools did not receive any financial aid. ${ }^{2}$

Our second set of hypotheses is that TVET students drop out more frequently when they are from families with parents that have characteristics associated with placing less value toward education. For example, it is known from the international literature that if parents have low levels of education, they are less likely to value education for their children (Filmer, 2000). These results have also been shown to hold true in the context of rural China (Jamison and Van der Gaag, 1987; Yi et al., 2012). Specifically, parents with lower levels of education may believe that education is unnecessary for future success in the labor market (Brown and Park, 2002). In addition, parents with low educational attainment may lack the ability to aid their children in learning (e.g., helping with homework), having never received the same level of education (Connelly and Zheng, 2003). It is for this reason that we hypothesize that students with parents with low levels of education will have higher rates of dropout.

Moreover, the migration status of students' parents might be associated with dropout. Parents in rural areas may be migrating to cities to work: one study shows that one or both parents of $18.1 \%$ of junior high school students are migrating (Du et al., 2005). Unfortunately, migrating parents are less able to care for or supervise their children's education, which in turn may potentially increase students' chances of dropping out (Hanson and Woodruff, 2003). In addition, migrating parents may serve as negative 'role models', influencing children to migrate themselves in the hope of increasing the probability of finding a job (Du et al., 2005). Indeed, Yi et al. (2012) found junior high students (as opposed to TVET students) are at risk of dropping out when their parents migrate. Battistella and Conaco (1998) and McKenzie and Rapoport (2011) provide similar evidence from the Philippines and Mexico, respectively.

Our third hypothesis is that students drop out from TVET because of low achievement. Low achievement may suggest to students that they are not capable of learning, or it signals unwillingness to do so (Vallerand et al., 1997). If students feel they are not capable of learning they may perceive low returns to attending school. This is especially true in competitive school systems, like that in China (Yi et al., 2012). If students with low achievement perceive that they will learn less in TVETs (and if guardians also perceive the same reality), they may decide to drop out because they predict the returns to TVET to be lower than other students (Clarke et al., 2000; Rumberger and Lim, 2008).

\section{Data and approach}

This paper draws on two waves of survey data collected by the authors in October 2011 and May 2012. To maximize external validity, we sampled TVET schools from two provinces (Shaanxi and Zhejiang). The two provinces differ greatly in terms of geography and economic development. Shaanxi province is an inland province in Northwest China. It has a Gross Domestic Product (GDP) per capita of 33,427 yuan (5305 US dollars-National Bureau of Statistics, 2012). Shaanxi ranks 15th among all provinces in terms of GDP per capita and has been among the slowest growing provinces in China during the 2000s (National Bureau of Statistics, 2012). By contrast, Zhejiang is a rich coastal province with a GDP per capita of almost twice that of Shaanxi: 59,157 yuan (9390 dollars-National Bureau of Statistics, 2012). Zhejiang is the fifth richest province in terms of per capita GDP after Tianjin, Shanghai, Beijing and Jiangsu (National Bureau of Statistics, 2012).
After selecting the two provinces, we chose the most populous prefectures within each province (three in Shaanxi and four in Zhejiang). The seven prefectures had more than 1000 uppersecondary TVET schools. Resource constraints prevented us from sampling all majors. As such, using administrative data, we identified the most popular major (i.e., the major with the largest enrollment) among upper-secondary TVET schools in each province: computers. Using official records, we excluded schools that reported having no computer majors. ${ }^{3}$ We then called the remaining schools to ask about the number of new (first-year) students enrolled in each school in autumn 2011. Schools that had fewer than 50 first-year students enrolled in the computer or computer-related major were also excluded. We ultimately sampled 52 schools in Shaanxi and 55 schools in Zhejiang for our study.

The next step was to choose which students in each school would be surveyed. In each school, we randomly sampled two firstyear computer major classes (one class if the school only had one computer major class). We sampled a total of 186 classes and a total of 7172 first-year students in these classes. The sample is representative of larger upper-secondary vocational schools with computer majors in the most populous prefectures in Zhejiang and Shaanxi provinces.

In October 2011 (near the beginning of the 2011-2012 academic year), our survey team administered a four-block student survey at each school (which we call the baseline survey). The first block collected information about family assets and access to financial aid. Students were asked to fill out a checklist of household durable assets. We subsequently assigned a value to each asset (based on the National Household Income and Expenditure Survey which is organized and published by National Bureau of Statistics (2012), and calculated a single metric of the value of family asset holdings for each student. This metric is used to measure student poverty. Other questions covered students' financial aid status, including how much need-based aid they received; schooling expenses, including tuition and housing costs per semester.

The other three blocks addressed issues of family/student characteristics and achievement in school. The second block gathered information on basic student information, including gender, age, and ethnicity. This block also included questions asking whether students had ever worked as a migrant worker. The third block asked about the families of students. This block included questions eliciting information about the education of parents and their migration status (whether parents stayed at home January-Augusst 2011), the occupation of the parents, and the number of siblings. The fourth block was used to collect our measures for achievement: two 25 min standardized mathematics and computer examinations. We administered the examinations ourselves (such that students had no time to prepare for the examinations beforehand) and proctored students closely. The summary statistics of these variables are presented in Table 1.

In May 2012 (near the end of the 2011-2012 academic year), we returned to these schools and administered a similar survey (which we call the endline survey). ${ }^{4}$ One of the primary purposes of the endline survey was to collect information on dropout

\footnotetext{
${ }^{3}$ We defined computer or computer-related majors by whether the official name of the major contained the word "computer." The most common major included was titled "computer applications," followed by computer maintenance, computer design, and computer programming.

4 The academic year should be nine months long for TVET schools in our sample provinces (September-June). However, enrollments did not stabilize in the sample schools until October (students were deciding between schools or deciding whether to attend TVET). In addition, schools were not uniform in their timing for summer break, forcing our enumerator teams to return to the schools in May. As such, the time between our survey waves is slightly shorter than the academic year.
} 
behavior. Following standards in the literature, we defined dropping out as a permanent departure from the school, thus excluding sick leave, transfers, or temporary leaves (Yi et al., 2012; Yi et al., 2012Yi et al., 2012, 2015; Wang et al., 2014). To measure dropout, we tracked down all students who participated in our baseline survey (i.e., were enrolled at the start of the school year) to determine their dropout status.

Specifically, our enumerators filled in a student tracking form for each class. This form contained a list of all the students who completed our baseline survey. During the endline survey, our enumerators marked each student as present, absent (e.g., sick), transferred (e.g., to another school), on leave, or dropped out. Initially, student leaders (in Chinese called ban zhang or class monitor) in the class provided this information. In most of the cases, the student leaders were sure about the status of the students that were absent. To ensure the quality of the responses, however, we exerted additional effort. If students were marked "dropped out" on our tracking form, our enumerators called the parents or guardians of the students to further ascertain whether students in fact dropped out. All (100\%) of dropouts were verified in this manner, with no discrepancies found. This procedure allowed us to accurately identify dropouts.

One of the primary purposes of the endline survey was to collect information on dropout behavior. To track students who participated in our baseline survey, our enumerators filled in a student tracking form for each class. This form contained a list of all the students who completed our baseline survey. During the endline survey, our enumerators marked each student as present, absent (e.g., sick), transferred (e.g., to another school), on leave, or dropped out (i.e., no longer enrolled in school). Initially, student leaders (in Chinese called ban zhang or class monitor) in the class provided this information. In most of the cases, the student leaders were sure about the status of the students that were absent. To ensure the quality of the responses, however, we exerted additional effort. If students were marked "dropped out" on our tracking form, our enumerators called the parents or guardians of the students to further ascertain whether students in fact dropped out. All (100\%) of dropouts were verified in this manner, with no discrepancies found. This procedure allowed us to accurately identify dropouts.

\section{Statistical approach}

In the first part of our analysis, we calculate simple descriptive statistics. The means of student and family background variables are estimated for the group of students that dropped out and the group of students that did not. We then conduct a two-tailed $t$-test to compare students who dropped out and those that did not for each variable. The standard errors for these $t$-tests are corrected for clustering at the school level.

To explore the determinants of dropout in a multivariate framework, we first use ordinary least squares (OLS) to estimate the following equation: ${ }^{5}$

$y_{i s}=\beta_{1} P_{i s}+\beta_{2} E_{i s}+\beta_{3} A_{i s}+\beta_{4} S_{i s}+\varepsilon_{\text {is }}$

We call this model our OLS model. Our dependent variable $y$ is a binary variable equaling 1 if student $i$ dropped out by the end of the 2011-2012 academic year in school $s$ (and 0 otherwise). The independent variables are the three possible vectors, representing our three hypotheses of poverty $(\boldsymbol{P})$, parental education and

\footnotetext{
${ }^{5}$ In the robustness check (reported below), we report the results of a logit model, given the limited nature of our dependent variable. The results using logit or OLS are substantively the same.
}

migration status $(\boldsymbol{E})$, and achievement $(\boldsymbol{A})$, as described in the hypothesis section.

The vector $\boldsymbol{P}$ includes variables for household asset ranking (the variable equals 1 if the household is in the lowest decile and equals 0 if the household is higher than the lowest decile), and access to financial aid (equals 1 if the student reports receiving any financial aid and 0 if not). The vector $\boldsymbol{E}$ includes parental education (two variables that equal 1 if the students' mother and father finished junior high school, respectively, and 0 if not) and parental migration status (two variables that equal 1 if the students' mother and father were away from home between January and August 2011, respectively, and 0 if not). The vector $\boldsymbol{A}$ includes math and computer test scores (standardized across the entire sample of test-takers, such that the mean is 0 and standard deviation is 1).

While we focus on the three sets of determinants above (poverty, parental education and migration status, achievement), we also control for other student background characteristics in our OLS model. Specifically, we add the vector $\boldsymbol{S}$ which includes the students' age (in years), gender (equals 1 if the student is male and 0 if female), ethnicity (equals 1 if the student is Han Chinese and 0 if otherwise), residential status (equals 1 if the student has rural residential status and 0 if urban), migration status (equals 1 if the student has migrated before and 0 otherwise), number of siblings, parental occupation (equals 1 if both parents are subsistence farmers and 0 if not), and where the student attends school (equals 1 if the student attends school in Zhejiang and 0 if in Shaanxi).

Because schools vary in quality, we also examine the three determinants of dropout after controlling for school fixed effects. Including school fixed effects allows us to correct bias due to students sorting across schools based on the three sets of determinants. For example, students from poor families may attend lower quality schools because they are financially constrained. More importantly, as high school entrance exam scores are important criteria for being accepted into upper-secondary TVET, students with low achievement are likely sorted into poor quality schools. Our school fixed effects model is specified as follows:

$y_{i s}=\beta_{1} \mathrm{P}_{i s}+\beta_{2} E_{i s}+\beta_{3} A_{i s}+\beta_{4} S_{i s}+\Gamma_{i s}+\varepsilon_{i s}$

In Eq. (2), we add the school fixed effects term $\Gamma_{s}$ to compare students only within the same schools. In all our equations, we use standard errors adjusted for clustering at the school level.

\section{Results}

\subsection{What is the dropout rate in Chinese upper-secondary TVET?}

According to our data, the dropout rate in our sample TVET schools is substantial. Of the 7172 upper-secondary TVET students, 768 of them dropped out in the first year (between our baseline and endline surveys). In others words, $10.7 \%$ of the sample TVET students that participated in the baseline survey dropped out before finishing their first year of school.

The dropout rate also varies across provinces, prefectures and schools. The results of our survey demonstrated that the dropout rate is $14.1 \%$ in Shaanxi. This was substantially higher than the dropout rate of $8.7 \%$ in Zhejiang. The higher dropout rate in Shaanxi compared to Zhejiang should not be surprising if any (or some or all) of the three hypotheses are valid. The poverty rate in Shaanxi Province $(8.5 \%)$ is much higher than that in Zhejiang Province

\footnotetext{
${ }^{6}$ In the Statistical Yearbook, the poverty rate is calculated by dividing the number of individuals who participate any government poverty funds/programs by the total
} number of individuals in the province. 
(1.3\%-National Bureau of Statistics, 2012). ${ }^{6}$ According the Yi et al. (2013), the academic achievement of upper-secondary TVET students in Zhejiang are also higher than those in Shaanxi. In the discussion below, we use non-aggregated, student-level data to understand exactly what types of students are dropping out.

The dropout rate also varies greatly across prefectures and schools. Almost $22 \%$ of students in one of the sample prefectures in Shaanxi dropped out before finishing their first year of TVET. In contrast, fewer than $3 \%$ of students in one of the sample prefectures in Zhejiang dropped out (Fig. 1). The dropout rates among schools with Shaanxi and Zhejiang also vary sharply. The range in Shaanxi is between $10 \%$ (the school in Shaanxi with the lowest rate of dropout) and $22 \%$. The range in Zhejiang is between $3 \%$ and $12 \%$. The fact that the dropout rate differs greatly by prefecture and even by school underlines the importance of controlling for school fixed effects in our analyses below.

Given that the dropout rate in the first year is $10.7 \%$, what percentage of students will complete all three years of uppersecondary TVET? Previous research suggests that dropout rates decline in the second and third years of schooling (Yi et al., 2012), so the lower bound of our estimate of TVET completion is $67.9 \%$ (100 minus 10.7 percentage points per year multiplied by 3 years). On the other hand, our survey period did not cover the summer vacation that students transit from the first academic year to the second academic year. In addition, although our data did not collect dropout rate in the second and third academic years, at the time of our endline survey, we asked the remaining students at school whether they planned to leave their school in the following year. Among the individuals remaining at school, $16.5 \%$ of students said they planned to drop out. Even if we assume that only half of these students will act on their plans over their next two years in school, this would still increase dropout rates by 7.4 percentage points $(16.5 / 2 \times(100-10.7))$. Thus, an upper bound estimate of the completion rate would be approximately $81.9 \%$, accompanied by a dropout rate of $18.1 \%(7.4+10.7)$.

As it turns out, even this conservative estimate of dropout ( $18.1 \%$ over three years) exceeds other comparable benchmarks. Only between $4.2 \%$ and $7.4 \%$ of students who enrolled in upper secondary academic school drop out before graduating over all three years (Shi et al., 2014). As an additional point of comparison, in OECD countries, the dropout rate in upper secondary education is less than $12 \%$ (OECD, 2008). Pakistan has a TVET dropout rate of $16.1 \%$ over three years (Janjua and Mohammad, 2008). Our conservative estimate of the dropout rate (18.1\%) would still exceed comparable upper-secondary dropout rates in China, in the OECD, and at least one other developing country. Thus, while these data strictly apply to only one major in the two provinces studied (albeit the most popular major in upper-secondary TVET in China),

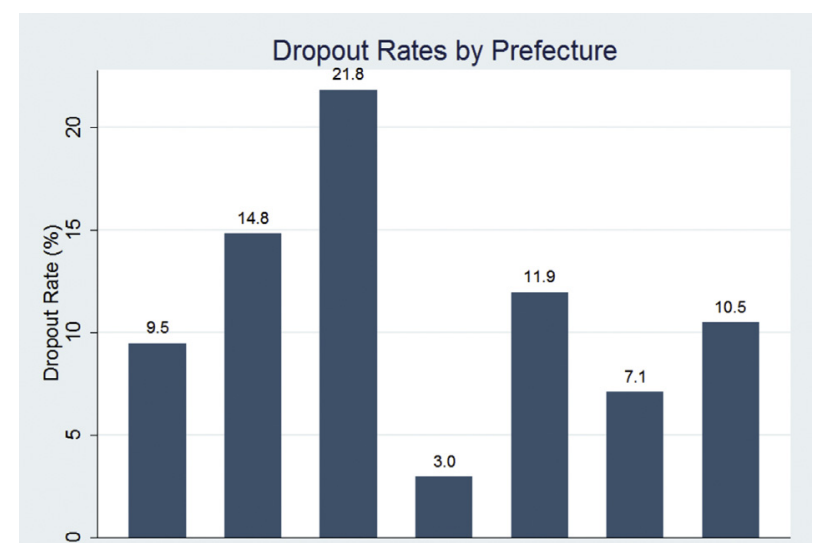

Fig. 1. Dropout rates across different prefectures. the dropout rate implied is sufficiently large that it should raise concern.

\subsection{Who is dropping out?}

With so many students dropping out, an important question to resolve is whether certain (and which) subgroups are more at risk of dropping out. In this subsection, we compare the factors of dropout one at a time to identify what kinds of students are more likely to drop out.

Our descriptive results show that dropouts and non-dropouts do not differ in terms of financial constraints. For example, although dropouts are about 2 percentage points more likely to be among households in the bottom decile in terms of household asset value, when subjected to a two-tailed $t$-test, this difference is not statistically significant (Table 2, row 8). In terms of financial aid, although students who dropped out were 3 percentage points less likely to receive financial aid when compared to non-dropouts, this difference is not statistically significant (row 9). In sum, dropouts do not seem to experience more financial constraints than their non-poor peers.

While dropouts do not necessarily have parents with lower educational attainment, their parents participate in migration at higher rates. Although only $45 \%$ of dropouts had fathers with junior high degrees, compared to $52 \%$ of non-dropouts (a 7 percentage point difference-Table 2 , row 12 ), this difference is not statistically significant. The same is true for mothers' education: dropouts are 4 percentage points less likely to have mothers with a junior high degree (row 13), but this finding is not statistically significant. By contrast, in terms of migration status, dropouts are less likely to have parents who were at home. Dropouts were less likely to have their fathers living at home with them: $29 \%$ of dropouts' fathers migrated, compared to only $23 \%$ among non-dropouts (row 14). Likewise, whereas $21 \%$ of mothers among dropouts migrated, only $13 \%$ among non-dropouts did so (row 15), a finding significant at the $10 \%$ level. In sum, dropping out seems to be associated with parents who are not at home (because they are migrating to cities to work).

Finally, dropouts tend to have poorer achievement in terms of math and computer scores. At the time of our baseline examination, dropouts had lower scores on both computer and mathstandardized exams than non-dropouts. Dropouts performed at -0.28 standard deviations (SDs), while non-dropouts performed at +0.034 SDs. In other words, dropouts scored 0.314 SDs lower $(0.034-(-.28))$ than on their non-poor counterparts in terms of mathematics (Table 2, row 10). Non-dropouts also scored 0.301 $(0.032+0.027)$ SDs higher on their computer skills test (row 11). As both of these findings are significant at the $10 \%$ level, we conclude that low-achieving students are therefore more likely to drop out of TVET.

\subsection{OLS and fixed effects models: further examinations of the hypotheses}

Similar to our bivariate results, our OLS and fixed effects models (both of which adjust for student control variables) show that financial constraints do not correlate with student dropout. In our OLS model, students living in households ranking in the lowest $10 \%$ in terms of household assets are only 0.7 percentage points more likely to drop out, a finding not statistically significant at the $10 \%$ level (Table 3, column 1, row 9). Furthermore, the OLS results show that dropouts and non-dropouts are exactly alike ( 0 percentage point difference) in terms of whether they receive any financial aid (column 1, row 10).

To further test this finding, we include school fixed effects (Table 3, column 2). The adjusted fixed-effects model also shows 
Table 1

Summary statistics.

Source: Author's survey

\begin{tabular}{|c|c|c|c|c|c|c|}
\hline & & Obs. & Mean & SD & Min & Max \\
\hline \multicolumn{7}{|c|}{ Student controls } \\
\hline 1. & Age (years) & 7149 & 16.2 & 1.17 & 12.3 & 42.9 \\
\hline 2. & Gender ( 1 = male $)$ & 7172 & 0.58 & 0.49 & 0 & 1 \\
\hline 3. & Ethnicity (1 = Han) & 6859 & 0.98 & 0.13 & 0 & 1 \\
\hline 4. & Has rural Hukou ( $1=$ yes $)$ & 7110 & 0.89 & 0.31 & 0 & 1 \\
\hline 5. & Migrated before ( 1 = yes) & 7079 & 0.19 & 0.39 & 0 & 1 \\
\hline 6. & Number of siblings & 7172 & 0.83 & 0.70 & 0 & 5 \\
\hline 7. & Both parents do farm work ( $1=$ yes) & 6889 & 0.20 & 0.40 & 0 & 1 \\
\hline \multicolumn{7}{|c|}{ Financial constraints } \\
\hline 8. & Asset value in lowest 10 percent $(1=$ yes $)$ & 7172 & 0.100 & 0.30 & 0 & 1 \\
\hline 9. & Receives financial aid or waivers $(1=$ yes $)$ & 7112 & 0.59 & 0.49 & 0 & 1 \\
\hline \multicolumn{7}{|c|}{ Achievement } \\
\hline 10. & Math test score (SD) & 7164 & $-4.7 e-09$ & 1.00 & -3.76 & 1.33 \\
\hline 11. & Computer test score (SD) & 7160 & $2.1 e-09$ & 1.00 & -4.02 & 3.04 \\
\hline \multicolumn{7}{|c|}{ Parental education and migration } \\
\hline 12. & Father completed junior HS ( 1 = yes) & 6742 & 0.51 & 0.50 & 0 & 1 \\
\hline 13. & Mother completed junior HS ( $1=$ yes) & 6650 & 0.41 & 0.49 & 0 & 1 \\
\hline 14. & Father migrated $(1=$ yes $)$ & 6815 & 0.24 & 0.42 & 0 & 1 \\
\hline 15. & Mother migrated $(1=$ yes $)$ & 6722 & 0.14 & 0.35 & 0 & 1 \\
\hline
\end{tabular}

Table 2

Results from $t$-test of differences between dropouts and non-dropouts, 2011-2012. Source: Author's survey

\begin{tabular}{|c|c|c|c|c|}
\hline & & $\begin{array}{l}\text { Non- } \\
\text { dropouts }\end{array}$ & Dropouts & $p$-values ${ }^{*}$ \\
\hline \multicolumn{5}{|c|}{ Student controls } \\
\hline & Age (years) & $\begin{array}{l}16.1 \\
(1.08)\end{array}$ & $\begin{array}{l}16.4 \\
(1.73)\end{array}$ & 0.24 \\
\hline & Gender $(1=$ male $)$ & $\begin{array}{l}0.58 \\
(0.49)\end{array}$ & $\begin{array}{l}0.61 \\
(0.49)\end{array}$ & 0.80 \\
\hline 3. & Ethnicity (1 = Han) & $\begin{array}{l}0.98 \\
(0.13)\end{array}$ & $\begin{array}{l}0.98 \\
(0.14)\end{array}$ & 0.71 \\
\hline 4. & Has rural Hukou (1 = yes) & $\begin{array}{l}0.89 \\
(0.31)\end{array}$ & $\begin{array}{l}0.92 \\
(0.27)\end{array}$ & 0.19 \\
\hline 5. & Migrated before ( 1 = yes) & $\begin{array}{l}0.18 \\
(0.39)\end{array}$ & $\begin{array}{l}0.22 \\
(0.41)\end{array}$ & 0.21 \\
\hline 6. & Number of siblings & $\begin{array}{l}0.82 \\
(0.69)\end{array}$ & $\begin{array}{l}0.92 \\
(0.73)\end{array}$ & 0.26 \\
\hline 7. & Both parents do farm work ( 1 = yes) & $\begin{array}{l}0.20 \\
(0.40)\end{array}$ & $\begin{array}{l}0.24 \\
(0.43)\end{array}$ & 0.50 \\
\hline \multicolumn{5}{|c|}{ Financial constraints } \\
\hline & $\begin{array}{l}\text { Asset value in lowest } 10 \text { percent } \\
(1=\text { yes })\end{array}$ & $\begin{array}{l}0.097 \\
(0.30)\end{array}$ & $\begin{array}{l}0.12 \\
(0.33)\end{array}$ & 0.40 \\
\hline & Receives financial aid ( 1 = yes) & $\begin{array}{l}0.60 \\
(0.49)\end{array}$ & $\begin{array}{l}0.57 \\
(0.50)\end{array}$ & 0.78 \\
\hline \multicolumn{5}{|c|}{ Achievement } \\
\hline & Math test score (SD) & $\begin{array}{l}0.034 \\
(0.99)\end{array}$ & $\begin{array}{l}-0.28 \\
(1.04)\end{array}$ & 0.06 \\
\hline & Computer test score (SD) & $\begin{array}{l}0.032 \\
(0.99)\end{array}$ & $\begin{array}{l}-0.27 \\
(1.07)\end{array}$ & 0.09 \\
\hline \multicolumn{5}{|c|}{ Parental education and migration status } \\
\hline 12. & Father completed junior HS (1 = yes) & $\begin{array}{l}0.52 \\
(0.50)\end{array}$ & $\begin{array}{l}0.45 \\
(0.50)\end{array}$ & 0.26 \\
\hline 13. & Mother completed junior HS ( 1 = yes) & $\begin{array}{l}0.41 \\
(0.49)\end{array}$ & $\begin{array}{l}0.36 \\
(0.48)\end{array}$ & 0.31 \\
\hline 14. & Father migrated ( 1 = yes) & $\begin{array}{l}0.23 \\
(0.42)\end{array}$ & $\begin{array}{l}0.29 \\
(0.45)\end{array}$ & 0.12 \\
\hline & Mother migrated ( 1 = yes) & $\begin{array}{l}0.13 \\
(0.34)\end{array}$ & $\begin{array}{l}0.21 \\
(0.40)\end{array}$ & 0.06 \\
\hline Obs & ervations & 6404 & 768 & \\
\hline
\end{tabular}

* All p-values calculated by a two tailed $t$-test (adjusted for clustering by school) for differences between the means of the two groups. that being poor does not predict dropout: students living in households ranked in the bottom decile are only 0.9 percentage points more likely to drop out (row 1, column 9). Moreover, they continue to be identical in terms of their access to financial aid (Table 3, row 2, column 10). Taken together, our analyses show that neither poverty nor access to financial aid correlate with student dropout. In other words, financial constraints do not seem to be driving students to drop out.

When examining our achievement-dropout hypothesis, our OLS results also mirror our descriptive results. Low math and computer test scores strongly predict dropout. For example, an increase of one SD in math scores decreases dropout rates by 1.8 percentage points (Table 3 , column 1 , row 11 ), a finding significant at the $1 \%$ level. Likewise, an increase of one SD in computer test scores decreases dropout rates by 1.3 percentage points (column 1 , row 12 ), a finding significant at the $5 \%$ level.

In our fixed effects model, we find that only computer scores (technical skills in the major) predict student dropout. That is, the coefficient for math test scores ( 0.6 percentage points) becomes statistically insignificant (column 2, row 12 ). However, within the same school and controlling for student characteristics, an increase of one SD on the computer test continues to reduce drop out by 1.3 percentage points, a finding significant at the $10 \%$ level (Table 3 , column 2, row 12).

When examining the association between parental education/ occupation and dropout, our OLS results differ slightly from our descriptive findings: we find that both parental education and migration status are associated with student dropout. Students whose fathers finished junior high are 1.9 percentage points less likely to drop out (significant at the $10 \%$ level-Table 3, column 1, row 13). Moreover, students whose mothers finished junior high are 2.4 percentage points less likely to dropout (significant at the 5\% level-column 1, row 14). Although students whose fathers migrated are 0.5 percentage points less likely to drop out, this finding is not statistically significant at even the $10 \%$ level (column 1 , row 15). In contrast to fathers, we find that students whose mothers migrated are 6.5 percentage points more likely to drop out (column 1, row 16). This result is significant at the $1 \%$ level.

In the fixed effects model, we find that only mothers' education and migration status matter. Although students whose fathers completed junior high schools are still less likely to drop out (by 1.6 percentage points), the finding is no longer significant (Table 3 , 
Table 3

Correlation of student dropout to financial constraints, student achievement, and parental education / migration status: OLS and Fixed Effects Models (2011-2012) Source: Author's Survey

OLS School Fixed Effects

(1) (2)

\begin{tabular}{|c|c|c|}
\hline Student controls & & \\
\hline 1. Attend school in Zhejiang ( $1=$ yes) & $\begin{array}{l}-0.072^{* * *} \\
(0.011)\end{array}$ & \\
\hline 2. Age (years) & $\begin{array}{l}0.001 \\
(0.004)\end{array}$ & $\begin{array}{l}-0.004 \\
(0.004)\end{array}$ \\
\hline 3. Gender $(1=$ male $)$ & $\begin{array}{l}-0.044^{* * * *} \\
(0.009)\end{array}$ & $\begin{array}{l}0.061^{* *} \\
(0.013)\end{array}$ \\
\hline 4. Ethnicity ( $1=$ Han $)$ & $\begin{array}{l}0.022 \\
(0.033)\end{array}$ & $\begin{array}{l}0.009 \\
(0.042\end{array}$ \\
\hline 5. Has rural Hukou ( $1=$ yes $)$ & $\begin{array}{l}0.022 \\
(0.012)\end{array}$ & $\begin{array}{l}0.014 \\
(0.012)\end{array}$ \\
\hline 6. Migrated before $(1=$ yes $)$ & $\begin{array}{l}0.017 \\
(0.011)\end{array}$ & $\begin{array}{l}0.021 \\
(0.012)\end{array}$ \\
\hline 7. Number of siblings & $\begin{array}{l}0.010 \\
(0.006)\end{array}$ & $\begin{array}{l}0.010 \\
(0.007\end{array}$ \\
\hline 8. Both parents do farm work ( $1=$ yes) & $\begin{array}{c}-0.007 \\
(0.011)\end{array}$ & $\begin{array}{l}-0.013 \\
(0.009)\end{array}$ \\
\hline Financial constraints & & \\
\hline 9. Asset value in lowest 10 percent $(1=$ yes $)$ & $\begin{array}{l}0.007 \\
(0.016)\end{array}$ & $\begin{array}{l}0.009 \\
(0.015)\end{array}$ \\
\hline 10. Receives financial aid or waivers ( $1=$ yes) & -0.000 & \\
\hline
\end{tabular}

$(0.008) \quad(0.012)$

Achievement

11. Math test score (SD)

12. Computer test score (SD)

$\begin{array}{ll}-0.018^{* * *} & -0.006 \\ (0.004) & (0.005) \\ -0.013^{* *} & -0.013^{*} \\ (0.005) & (0.005)\end{array}$

Parental education and migration status 13. Father completed junior HS ( $1=$ yes $)$

14. Mother completed junior HS ( $1=$ yes)

15. Father migrated $(1=$ yes $)$

16. Mother migrated $(1=$ yes $)$

Constant

Observations

$R^{2}$

Robust standard errors (adjusted for clustering by school) in parentheses.

${ }^{*} p<0.1$.

$p<0.05$.

$p<0.01$.

column 2, row 13). Likewise, students whose fathers migrated are 1 percentage point less likely to drop out. However, this finding also is not statistically significant (column 2, row 15 ). On the other hand, if a student's mother finished junior high school, the student was 2 percentage points less likely to drop out, a finding significant at the $10 \%$ level (column 3, row 2). Moreover, if mothers migrate, their children are 6.2 percentage points more likely to drop out, a finding significant at the $1 \%$ level (column 3, row 2). In sum, mothers' (but not fathers') education and migration status seem to protect student against dropout.

\subsection{Robustness checks}

Although our outcome for dropout (whether a student was present in October 2011 but dropped out by May 2012) is a binary variable, we have reported OLS estimates. We do so for ease of interpretation, combined with the fact that all covariates in Eq. (1) (with the exception of student age, number of siblings, and math/ computer achievement) are dummy variables. In the extreme case of a fully saturated model (where all variables are dummy variables), the linear probability model is completely general and has the fitted probabilities within the interval [0,1] (Angrist, 2001; Wooldridge, 2002). As a robustness check, we conducted logit school fixed effects, reporting marginal effects at the mean. The results are substantively identical to our OLS results, with the statistically significant results in our fixed effects model consistent with the statistically significant results in the logit model (Appendix Table A1).

\section{Discussion and conclusion}

Using a large dataset collected in two Chinese provinces, we find that the dropout rate among first-year computer-major students in TVET is $10.7 \%$. The dropout rate is higher in Shaanxi (14.1\%) than in Zhejiang (8.7\%), and different prefectures have widely varying dropout rates (from $3 \%$ to $22 \%$ ). We estimate that at least $18.1 \%$ of students and up to $32 \%$ of students will drop out before completing upper-secondary TVET across these two provinces.

Granted, one limitation of our study is that we focus only on students in the computer major in two provinces. Ideally, our study would have included students in other majors (such as accounting) and included additional provinces. Strictly speaking, our results do not apply to other majors and provinces in China. Nonetheless, we note that the computer major is the most common TVET major taught in the two provinces (46\% of TVET schools in Zhejiang and $49 \%$ of TVET schools in Shaanxi offer the computer major). This makes the conclusions of the study applicable to a broader number of schools than any another major-even with the limitations that they do not strictly apply to other majors.

Our study also allowed us to identify the determinants of dropout. After controlling for a number of student background factors (and even school fixed effects), we find that there are two strong determinants of student dropout in TVET. First, students with low achievement tend to drop out. Second, students whose mothers lack a junior high degree or migrate are more likely to dropout. In most basic terms, students with low achievement and students that lack maternal care are most susceptible to dropout.

One of the surprising findings in this study is that financial constraints do not seem to correlate with dropout. In fact, students in the lowest decile of asset values had an average asset value of 1835 RMB (roughly 300 dollars), which is roughly one year of direct costs to attend TVET. Moreover, receiving financial aid (which alleviates financial constraints) does not seem to correlate with lower dropout rates. Why don't financial constraints matter?

One reason why financial constraints may not matter is that children whose families could not afford to send them to TVET dropped out before attending upper-secondary school. In other words, a selection process exists, where only students from relatively well-off households enroll in upper-secondary education. Brown and Park (2002) find in their sample of primary and junior high school students that $13.9 \%$ primary school students are poor and credit constrained, while only 6.9\% junior high school students are (note that Brown and Park's data was from 1999, before primary and junior high school were made free). We cannot make the same comparison with our data, but we think that the same process exists for the junior high school to TVET transition. That is to say, the most financially deprived students do not choose to enroll in TVET.

Moreover, the students who decided to enroll in TVET (and their parents/guardians) already accounted for high opportunity costs. Most students who drop out enter the workforce as unskilled labor (Song et al., 2013). Almost $100 \%$ of students who enter the workforce as unskilled laborers can find jobs. Indeed, according to 
a five-city China Urban Labor Survey, there is currently a shortage of unskilled labor in China. As a result, wages, especially for rural migrants, are increasing at 8-10\% per year (Han and Yuan, 2009; Hannum and Park, 2007 Hannum and Park, 2007). The opportunity costs are such that approximately $25 \%$ of students from poor junior high schools drop out before completing compulsory education (Yi et al., 2012). By contrast, families who enroll their children in TVET are likely to believe that attending a TVET program yields net benefits (i.e., increase in wages minus tuition and the foregone income from sending their children to work for three years in the labor market).

A second surprising result was that the education and migration status of mothers matters but not the education and migration status of fathers. Why is it that mothers matter but not fathers (in this case)? The importance of maternal education over paternal education on child's education is documented in previous studies (see, for example, Knight and Song, 2000; Li et al., 2005). While we cannot say for sure, it may be that maternal education correlates positively with the quality of mother-child interaction and maternal supervision over children's schooling. These factors may be the ones that contribute to keeping kids in school. If a father is less involved with his child's education (as is often the case in rural China) compared to the mother, his level of education may have less effect on student dropout. Our results also seem to suggest that if mothers are actively engaged in encouraging the student to stay in school, maternal care is indeed a protective element against dropout. This care, of course, is lost when the mother migrates away from home. It is perhaps for this reason that the effect of mother's migration status is so large and statistically significant.

Third, students with low achievement in technical skills tend to drop out. One of the most likely reasons for their decision is that these students feel like they are the least prepared to do well in their major in TVET. Whereas doing well in mathematics is not critical to their success in TVET, they might see that the returns to continuing in TVET fall below the costs.

The reasons underlying why students may be dropping out of TVET suggest certain policy directions. Governments should begin focusing attention on students at risk of dropping out: those lacking maternal care and low achievement (especially in terms of their technical skills). Upper-secondary TVET schools may consider programs focusing on emotional or social needs of students, such as counseling programs encouraging them to persist in school or helping them identify their future goals. Remedial tutoring might be offered for students who are not keeping up in class.

Notably, this discussion has sought to identify individual and family characteristics of students as the key driver of dropout. By using a school fixed effects model, we focused on the extent to which individual factors are predicting dropout rates. However, if the quality of a school system is defined by how much a student learns in such a system and how much the system contributes to increases in their future earnings, dropout may also be driven by (for example) deficiencies in school quality. In low-quality schools, students experience less learning than they (or their guardians) expect or desire.

In this way, the high rates of dropout just during the first year (10.7\%, and up to $22 \%$ in some prefectures) suggest potential problems in TVET quality (e.g., the value-added in terms of student learning). While the individual and family characteristics of students does lead them to drop out independently of their experiences at school (as shown in this study), high dropout rates would suggest deficiencies in TVET quality. That is, if students are dropping out at such high rates, we conjecture that one very likely reason is that they (or their guardians) experience or at least perceive few gains in knowledge or skills from attending TVET. Granted, it is true that dropout decisions are not made solely on cost-benefit decisions.
However, one of the most important reasons that families and students attend upper-secondary TVET is because they seek to learn skills and techniques that can increase their returns in the labor market. For this reason, we recommend that aggressive expansion of TVET be balanced with equal policy attention to educational quality in schools. Indeed, even without considering the quality implications, the high dropout rate is undermining the massive investments in TVET today by reducing the number of individuals who begin but do not actually complete TVET.

\section{Acknowledgements}

The authors acknowledge the financial assistance of the National Natural Science Foundation of China (grant number 71110107028 and 71333012 ), the International Initiative for Impact Evaluation (3IE OW2.208), and the Ford Foundation in supporting data collection for this study. Hongmei YI also had support from the Bingwei Excellent Young Scientist Program (grant number 2013RC204) at Institute of Geographical Sciences and Natural Resources Research, Chinese Academy of Sciences.

\section{Appendix}

\section{See Table A1}

Table A1

Correlation of student dropout to financial constraints, student achievement, and parental education/migration status: logit school fixed effects model. Source: Author's Survey

\begin{tabular}{|c|c|c|}
\hline & $\begin{array}{l}\text { Odds } \\
\text { ratio }\end{array}$ & Margins (at the mean) \\
\hline \multicolumn{3}{|l|}{ Student controls } \\
\hline 1. Age (years) & $\begin{array}{c}-0.041 \\
(0.040)\end{array}$ & $\begin{array}{r}-0.010 \\
(0.040)\end{array}$ \\
\hline 2. Gender $(1=$ male $)$ & $\begin{array}{l}0.746^{* * *} \\
(0.139)\end{array}$ & $\begin{array}{l}0.176^{* * *} \\
(0.139)\end{array}$ \\
\hline 3. Ethnicity $(1=$ Han $)$ & $\begin{array}{l}0.102 \\
(0.471)\end{array}$ & $\begin{array}{l}0.024 \\
(0.471)\end{array}$ \\
\hline 4. Has rural Hukou ( $1=$ yes $)$ & $\begin{array}{l}0.189 \\
(0.169)\end{array}$ & $\begin{array}{l}0.045 \\
(0.169)\end{array}$ \\
\hline 5. Migrated before $(1=$ yes $)$ & $\begin{array}{l}0.235^{*} \\
(0.119)\end{array}$ & $\begin{array}{l}0.055^{*} \\
(0.119)\end{array}$ \\
\hline 6. Number of siblings & $\begin{array}{l}0.092 \\
(0.071)\end{array}$ & $\begin{array}{l}0.022 \\
(0.071)\end{array}$ \\
\hline \multicolumn{3}{|l|}{ Financial constraints } \\
\hline 8 . Asset value in lowest 10 percent $(1=$ yes $)$ & $\begin{array}{l}0.090 \\
(0.144)\end{array}$ & $\begin{array}{l}0.021 \\
(0.144)\end{array}$ \\
\hline 9. Receives financial aid or waivers $(1=$ yes $)$ & $\begin{array}{l}0.011 \\
(0.122)\end{array}$ & $\begin{array}{l}0.003 \\
(0.122)\end{array}$ \\
\hline \multicolumn{3}{|l|}{ Achievement } \\
\hline 10. Math test score (SD) & $\begin{array}{l}-0.054 \\
(0.053)\end{array}$ & $\begin{array}{l}-0.013 \\
(0.053)\end{array}$ \\
\hline 11. Computer test score (SD) & $\begin{array}{c}-0.139 \\
(0.060)\end{array}$ & $\begin{array}{c}-0.033^{*} \\
(0.060)\end{array}$ \\
\hline \multicolumn{3}{|l|}{ Parental education and migration status } \\
\hline 12. Father completed junior HS ( $1=$ yes $)$ & $\begin{array}{l}-0.179 \\
(0.118)\end{array}$ & $\begin{array}{l}-0.042 \\
(0.118)\end{array}$ \\
\hline 13. Mother completed junior HS ( $1=$ yes) & $\begin{array}{c}-0.249^{*} \\
(0.107)\end{array}$ & $\begin{array}{l}-0.059^{*} \\
(0.107)\end{array}$ \\
\hline 14. Father migrated $(1=$ yes $)$ & $\begin{array}{l}-0.072 \\
(0.118)\end{array}$ & $\begin{array}{c}-0.017 \\
(0.118)\end{array}$ \\
\hline 15. Mother migrated $(1=$ yes $)$ & $\begin{array}{l}0.616^{* * *} \\
(0.138)\end{array}$ & $\begin{array}{l}0.145^{* * *} \\
(0.138)\end{array}$ \\
\hline Observations & 5609 & 5609 \\
\hline Pseudo $R^{2}$ & 0.028 & 0.028 \\
\hline
\end{tabular}

Robust standard errors in parentheses. ${ }^{* *} p<0.05$.

${ }_{* * * *}^{*} p<$

$p<0.01$. 


\section{References}

ACE Europe, 2008. "Evaluation of the TVET Policy and Practice of ICCO, Woord en Daad and Edukans." Technical Report, ACE Europe. Asian Development Bank. . "Education and Skills: Strategies for Accelerated Development in Asia and the Pacific." Technical Report. Asian Development Bank.

Angrist, J.D., 2001. Estimation of limited dependent variable models with dummy endogenous regressors. J. Bus. Econ. Stat. 19 (1), 2-28.

Battistella, G., Conaco, M.C.G., 1998. The impact of labour migration on the children left behind: a study of elementary school children in the Philippines. SOJOURN: J. Social Issues Southeast Asia 13 (2), 220-241.

Brown, P.H., Park, A., 2002. Education and poverty in rural China. Econ. Educ. Rev. 21 (6), 523-541.

China State Council, 2010. National Outline for Medium and Long-term Education Reform and Development (2010-2020).

Clarke, M., Haney, W., Madaus, G., 2000. High Stakes Testing and High School Completion, vol. 1. National Board on Educational Testing and Public Policy.

Connelly, R., Zheng, Z., 2003. Determinants of school enrollment and completion of 10 to 18 year olds in China. Econ. Educ. Rev. 22 (4), 379-388.

Du, Y., Park, A., Wang, S., 2005. Migration and Rural Poverty in China. J. Comp. Econ. 33 (4), 688-709 Symposium: Poverty and Labor Markets in China.

Dynarski, S., Scott-Clayton, J.E., 2008. Complexity and Targeting in Federal Student Aid: A Quantitative Analysis (No. w13801). National Bureau of Economic Research..

Filmer, D., 2000. The Structure of Social Disparities in Education: Gender and Wealth. World Bank Policy Research Working Paper (2268).

Fo, Z., Xing, H., 2011. Survey on the implementation of the national stipend policy in secondary vocational schools. In: Yang, D. (Ed.), The China Educational Development Yearbook. Brill, Leiden, The Netherlands vol. 3.

Gao, R., 2010. Student dropout in one secondary vocational school in northwest region. Chin. Voc. Tech. Educ. 10, 37-39.

Gao, S., 2011. Causes and solutions for secondary vocational school dropout. Voc. Educ. Res. 11, 54-56.

Guo, Z., Lamb, S., 2010. International Comparisons of China's Technical and Vocational Education and Training System, vol. 12. Springer.

Hannum, E., Park, A., 2007. Education and Reform in China. Routledge.

Hannum, E., 2003. Poverty and basic education in rural china: villages, households, and girls' and boys' enrollment. Comp. Educ. Rev. 47 (2), 141-159.

Hanson, G.H., Woodruff, C., 2003. Emigration and Educational Attainment in Mexico. Working Paper. University of California, San Diego.

Jamison, D.T., Van der Gaag, J., 1987. Education and earnings in the People's Republic of China. Econ. Educ. Rev. 6 (2), 161-166 Special Issue: Economics of Education: Tackling the New Policy Issues-The Dijon Papers.

Janjua, Y., Mohammad, I., 2008. Situation Analysis to Support the Program Design Process for National Skills Strategy of the Islamic Republic of Pakistan.

Jordan, M., Lamamra, N., Masdonati, J., 2009. Dropout rates in vocational education and training: a failure of the school-to-work transition? In: Rauner, F., Smith, E., Hauschildt, U., Zelloth, H. (Eds.), Innovative Apprenticeships: Promoting Successful School-to-Work Transitions. LIT Verglag, Berlin, pp. 57-61 September.

Knight, J., Song, L., 2000. Differences in Educational Access in Rural China. In: American Economics Association Annual Meeting, 7-9.
Kuczera, M., Field, S., 2010. Learning for Jobs OECD reviews of Vocational Education and Training: Options for China. Technical Report. Organization for Economic Cooperation and Development (OECD).

Li, H., Yao, X., Zhang, J., Zhou, L.A., 2005. Parental childcare and children's educational attainment: evidence from China. Appl. Econ. 37 (18), 2067-2076.

Li, H., Meng, L., Shi, X., Wu, B., 2013. Poverty in China's colleges and the targeting of financial aid. China Q. 216, 970-992.

Liu, C., Zhang, L., Luo, R., Rozelle, S., Sharbono, B., Shi, Y., 2009. Development challenges, tuition barriers, and high school education in China. Asia Pac. J. Educ. 29 (4), 503-520.

Loyalka, P., Liu, C., Song, Y., Yi, H., Huang, X., Wei, J., Zhang, L., Shi, Y., Chu, J., Rozelle, S., 2013. Can information and counseling help students from poor rural areas go to high school? Evidence from China. J. Comp. Econ. 41 (4), 1012-1025.

McKenzie, D., Rapoport, H., 2011. Can migration reduce educational attainment? Evidence from Mexico. J. Popul. Econ. 24 (4), 1331-1358.

Ministry of National Education, 2006. Rencana Strategis Departemen Pendidikan National Tahun 2005-2009. Ministry of National Education.

National Bureau of Statistics, 2001. China Statistical Yearbook 2000. China Statistics Press, Beijing, pp. 2001.

National Bureau of Statistics, 2012. China Statistical Yearbook 2011. China Statistics Press, Beijing, pp. 2012.

National Congress, 2011. Institui o Programa Nacional de Acesso ao Ensino Técnico e Emprego (Pronatec). Law 10.

OECD, 2008. Cutting School Drop-out Rates Key to Improve Job Prospects for Disadvantaged Youth-OECD Report. http://www.oecd.org/general/ cuttingschooldrop-outrateskeytoimprovejobprospectsfordisadvantagedyouthoecdreport.htm (accessed 11.02.15.).

Rumberger, R., Lim, S.A., 2008. Why students drop out of school: a review of 25 years of research. California Dropout Research Project. Policy Brief, 15.

Shi, Y., Zhang, L., Ma, Y., Yi, H., Liu, C., Johnson, N., Chu, J., Loyalka, P., Rozelle, S., 2014. Dropout in rural China's secondary schools: a mixed-methods analysis. China $\mathrm{Q}$ (Forthcoming).

UNESCO, 2012a. Transforming Technical and Vocational Education and Training: Building Skills for Work and Life. UNESCO Working Document.

UNESCO, 2012. Proposed Indicators for Assessing Technical and Vocational Education and Training. UNESCO Working Document, http://www.etf.europa. eu/webatt.nsf/0/E112211E42995263C12579EA002EF821/\$file/Report\%20on\% 20indicators\%20April\%202012.pdf. (accessed 28.10.14.).

UNESCO-UNEVOC, 2012. World TVET Database: Netherlands. http://www.unevoc. unesco.org/worldtvetdatabase1.php?ct=NLD.

Vallerand, R.J., Fortier, M.S., Guay, F., 1997. Self-determination and persistence in a real-life setting: toward a motivational model of high school dropout. J. Personality Social Psychol. 72, 1161-1176.

Wang, R., 2012. To phase in free vocational secondary education for all: not so fast. Educ. Econ. 2, 1-6.

Wooldridge, J.M., 2002. Econometric Analysis Cross Section Panel. MIT Press, Cambridge.

Yi, H., Zhang, L., Luo, R., Shi, Y., Mo, D., Chen, X., Brinton, C., Rozelle, S., 2012. Dropping out: why are students leaving junior high in China's poor rural areas? Int. J. Educ. Dev. 32 (4), 555-563.

Yi, H., Zhang, L., Liu, C., Yue, A., Yang, C., Chu, J., Loyalka, P., Maani, M., Wei, J., 2013. A report card: how are secondary vocational schools in China measuring up to government benchmarks? China World Econ. forthcoming. 